\title{
Aerogels for Biomedical, Energy and Sensing Applications
}

\author{
Muhammad Tayyab Noman 1,*®D, Nesrine Amor ${ }^{1} \oplus$, Azam Ali ${ }^{2}$, Stanislav Petrik ${ }^{3}$, Radek Coufal ${ }^{4}$, Kinga Adach ${ }^{3}$ \\ and Mateusz Fijalkowski ${ }^{3}$ (1)
}

1 Department of Machinery Construction, Institute for Nanomaterials, Advanced Technologies and Innovation (CXI), Technical University of Liberec, 46117 Liberec, Czech Republic; nesrine.amor@tul.cz

2 Department of Materials Engineering, Faculty of Textile Engineering, Technical University of Liberec, 46117 Liberec, Czech Republic; azam.ali@tul.cz

3 Department of Advanced Materials, Institute for Nanomaterials, Advanced Technologies and Innovation (CXI), Technical University of Liberec, 46117 Liberec, Czech Republic; stanislav.petrik@tul.cz (S.P.); Kinga.Adach@tul.cz (K.A.); mateusz.fijalkowski@tul.cz (M.F.)

4 Department of Science and Research, Faculty of Health Studies, Technical University of Liberec, 46117 Liberec, Czech Republic; radek.coufal@tul.cz

* Correspondence: muhammad.tayyab.noman@tul.cz; Tel.: +420-776396302

Citation: Noman, M.T.; Amor, N.; Ali, A.; Petrik, S.; Coufal, R.; Adach, K.; Fijalkowski, M. Aerogels for Biomedical, Energy and Sensing Applications. Gels 2021, 7, 264. https://doi.org/10.3390/ gels7040264

Academic Editors: Zhi Li, Xudong Cheng and Song He

Received: 12 November 2021 Accepted: 12 December 2021 Published: 14 December 2021

Publisher's Note: MDPI stays neutral with regard to jurisdictional claims in published maps and institutional affiliations.

Copyright: (c) 2021 by the authors. Licensee MDPI, Basel, Switzerland. This article is an open access article distributed under the terms and conditions of the Creative Commons Attribution (CC BY) license (https:// creativecommons.org/licenses/by/ $4.0 /)$.
Abstract: The term aerogel is used for unique solid-state structures composed of three-dimensional (3D) interconnected networks filled with a huge amount of air. These air-filled pores enhance the physicochemical properties and the structural characteristics in macroscale as well as integrate typical characteristics of aerogels, e.g., low density, high porosity and some specific properties of their constituents. These characteristics equip aerogels for highly sensitive and highly selective sensing and energy materials, e.g., biosensors, gas sensors, pressure and strain sensors, supercapacitors, catalysts and ion batteries, etc. In recent years, considerable research efforts are devoted towards the applications of aerogels and promising results have been achieved and reported. In this thematic issue, ground-breaking and recent advances in the field of biomedical, energy and sensing are presented and discussed in detail. In addition, some other perspectives and recent challenges for the synthesis of high performance and low-cost aerogels and their applications are also summarized.

Keywords: aerogels; silica aerogels; porous materials; catalysts; sensors

\section{Introduction}

The term aerogel is used for ultralow density and lightweight materials derived from organic, inorganic or hybrid molecular precursors. Aerogels contain $99.9 \%$ air in their structure, which makes a chain of porous network. Therefore, aerogels are solids similar to gel that contain air pockets [1]. Scientifically, aerogels are highly porous, light-weight and unique solid-state structures composed of three dimensional (3D) interconnected networks filled with a huge number of air pores [2]. These air-filled pores enhance the physicochemical properties and the structural characteristics in macroscale as well as integrate typical characteristics of aerogels, e.g., low density, high porosity and some specific properties of their constituents $[3,4]$. These extraordinary and attractive characteristics endow aerogels as a first choice in highly sensitive sensing and energy applications, e.g., biosensors [5,6], gas sensors [7], pressure strain sensors [8], supercapacitors [9], catalysts [10,11], energy storage [12,13], piezoelectric [14], thermal insulators [15,16] and ion batteries [17]. The term aerogel was coined by Kistler in the early 1931 to describe his synthesized gels, where the liquid was replaced with a gas without collapsing the solid gel structure [18]. In the beginning, there was limited research work on aerogels after their first discovery; the term aerogel had a rebirth in the 1970s for the popularity of sol-gel synthesis methods and the application of aerogels for storing rocket fuels. Afterwards, significant efforts were made to simplify the synthesis methods, especially drying, for low-cost and facile synthesis of 
aerogels. This opened the gateway for a variety of aerogels, due to their open structure and light-weight characteristics in different fields of applications.

The global development and continuous improvement in daily lifestyle have posed a burden on natural energy sources such as fossil fuels. The scarcity of these traditional resources and their impact on the surrounding environment has created challenges for mankind. In order to decrease this burden, research work has been carried out in different directions. One such direction is to rely on renewable energy sources such as solar energy. The conversion of concentrated solar energy into thermal or electricity is under the consideration of the scientific community. In this regard, porous materials provide a good solution for improving the heat transfer characteristics in solar systems [19-21]. Porous materials with their exceptional characteristics, i.e., low cost, light-weight and significant potential to augment thermal properties, have received considerable attention. These materials are used in different industrial applications, e.g., thermal insulation devices, adsorption devices, energy storage devices, geothermal devices and evaporating devices, due to their porosity and solid matrix structure [22]. The formation of a 3D network is a key factor in the synthesis of aerogels, with better durability, stability and higher porosity. Wet chemical methods are known as conventional methods to fabricate different types of aerogels, including inorganic, organic and hybrid, and sol-gel synthesis is one of the most prominent wet chemical methods for aerogel preparation [23]. Sol-gel method is generally completed by mixing precursors, followed by hydrolysis, polycondensation and then gelation, aging and finally drying by appropriate methods (ambient drying, super critical drying, freeze-drying or lyophilization). In sol-gel synthesis, each step is realized by the relevant variables, i.e., $\mathrm{pH}$ of the solution, concentration of precursors, time, temperature and type of solvents in order to fine-tune the final properties of the aerogels. Acidic and basic catalysts are used during hydrolysis and polycondensation reactions, depending on the materials to be catalyzed; the reaction is catalyzed. The drying of the gel is the key step among all the mentioned steps, which determines the overall efficiency and final properties of the aerogels. To date, the most intensive and significantly used drying methods for the preparation of aerogels are ambient drying (evaporation), freeze-drying (lyophilization) and super critical drying. Figure 1 shows a schematic illustration of the conventional aerogel synthesis procedure [24].

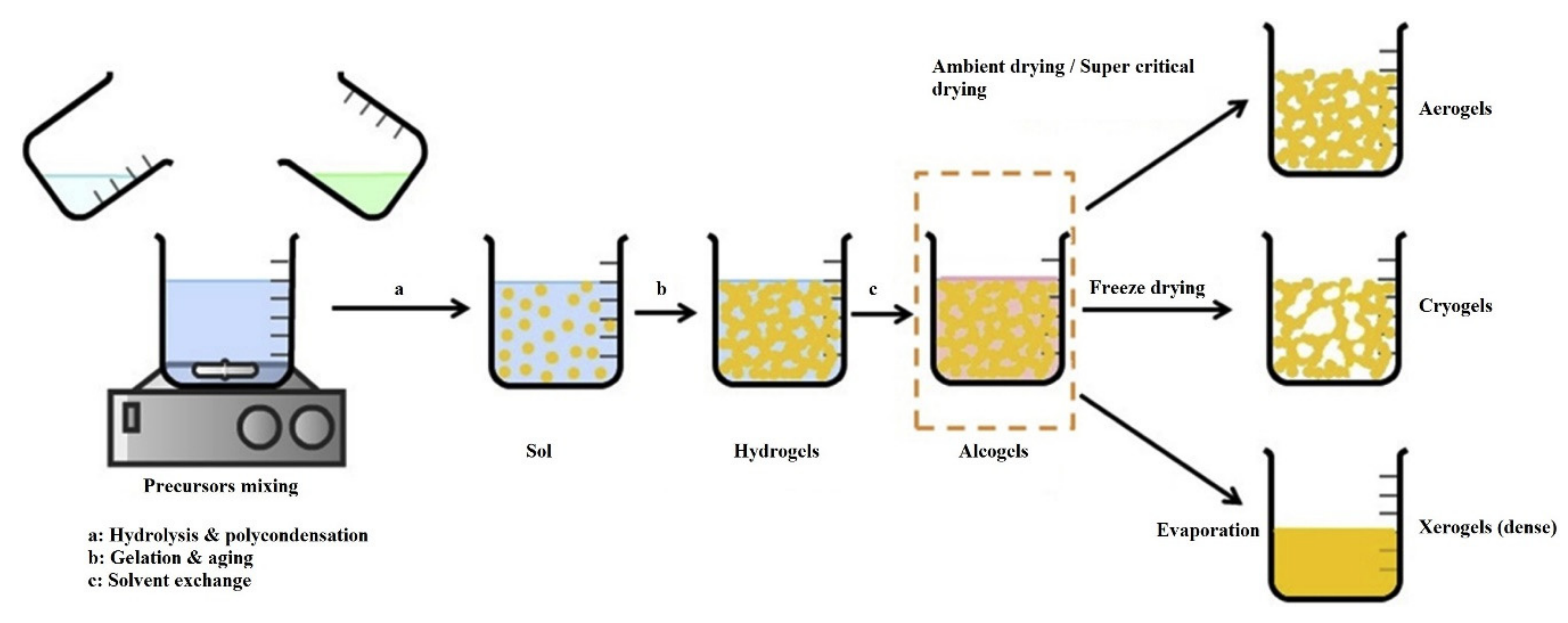

Figure 1. A schematic illustration of the conventional synthesis method of aerogels. Reprinted with permission from [24].

The procedure illustrated above has been mainly used and reported for aerogels. All other aerogel production techniques are either derived or altered from this procedure. Many researchers synthesized various types of aerogels, including organic aerogels [25], silicabased aerogels [26], metallic aerogels [27], carbon aerogels [28], chalcogenide aerogels [29] and hybrid aerogels [30] by this method [31,32]. Intensive research studies were carried out on the applications of aerogels in the past few years, indicating the great field of application 
for aerogels. There are many review papers available on the applications of aerogels; however, this work is related to aerogels made of different materials, i.e., carbon, gold, silver, zinc, titanium, cobalt and cellulose for biomedical, energy and sensing applications. We compared the significance of other materials, especially cellulose, carbon and some metals, with silica aerogels and demonstrated their importance for biomedical, energy and sensing applications. Among other potential applications, sensors have gained tremendous attention because they are vital in health monitoring, public safety, environment and industries, and aerogels have demonstrated their worth as an excellent material for sensors. The aim of this paper is to provide an up-to-date study on the applications of aerogels in energy, environment and sensing forms.

\section{Properties and Classification of Aerogels}

Aerogels are considered ultra-high nano-porous structures. These structures enable aerogels to be optimal candidates for many sensitive fields of applications, including energy, sensors and thermal protection. However, aerogels display mostly brittle behavior; for thermal insulation of complex geometrical structures, this type of mechanical behavior is not suitable because flexibility of the material is a primary concern. To allow certain flexibility in the aerogel structures, research efforts had been made and materials synthesized, which can be divided into two main categories, i.e., induced flexible and inherently flexible aerogels. Most of the flexible aerogels that are commercially available belong to induced-flexible aerogels, where the flexibility of the structure is induced by additives and components other than the aerogel material itself. Aerogels are classified into organic, inorganic and hybrid aerogels according to the type of precursor used during the synthesis of aerogels. However, according to their surface chemical properties, they are categorized into hydrophobic and hydrophilic aerogels. Table 1 shows the structural characteristics of aerogels reported by various studies. As shown in the table, particle size and surface area of the aerogels range between $2 \mathrm{~nm}$ to $5 \mathrm{~mm}$ and 300 to $1100 \mathrm{~m}^{2} \cdot \mathrm{g}^{-1}$, respectively. The density and porosity range between $40-350 \mathrm{~kg} \cdot \mathrm{m}^{-3}$ and $85-99.9 \%$, respectively. The pore diameter varies from $1-109.5 \mathrm{~nm}$ and thermal conductivity between $0.01-0.02 \mathrm{~W} \cdot \mathrm{m}^{-1} \cdot \mathrm{K}^{-1}$, respectively.

Table 1. Structural characteristics of different aerogels.

\begin{tabular}{|c|c|c|c|c|c|c|c|}
\hline Aerogel Type & Precursor & $\begin{array}{c}\text { Surface Area } \\
{\left[\mathrm{m}^{2} \cdot \mathrm{g}^{-1}\right]}\end{array}$ & $\begin{array}{c}\text { Density } \\
{\left[\mathrm{kg} \cdot \mathrm{m}^{-3}\right]}\end{array}$ & Porosity & Pore Size & $\begin{array}{c}\text { Thermal } \\
\text { Conductivity } \\
{\left[\mathrm{W} \cdot \mathbf{m}^{-1} \cdot \mathrm{K}^{-1}\right]}\end{array}$ & Reference \\
\hline Silica aerogels & $\mathrm{C}_{4} \mathrm{H}_{12} \mathrm{O}_{3} \mathrm{Si}$ & $600-1000$ & 350 & $85-99.9 \%$ & $1-100 \mathrm{~nm}$ & $0.010-0.020$ & [33] \\
\hline Silica aerogels & $\mathrm{Na}_{2} \mathrm{SiO}_{3}$ & $600-1000$ & $300-350$ & - & $20 \mathrm{~nm}$ & - & [34] \\
\hline Silica aerogels & $\mathrm{C}_{4} \mathrm{H}_{12} \mathrm{O}_{3} \mathrm{Si}$ & 576 & 100 & $>90 \%$ & $20-100 \mathrm{~nm}$ & 0.020 & [35] \\
\hline Silica aerogels & $\mathrm{Na}_{2} \mathrm{SiO}_{3}$ & 366 & $40-150$ & $>90 \%$ & $20-100 \mathrm{~nm}$ & - & [36] \\
\hline Silica aerogels & $\mathrm{Na}_{2} \mathrm{SiO}_{3}$ & $300-400$ & $50-80$ & $98 \%$ & $20-40 \mathrm{~nm}$ & $0.016-0.020$ & [37] \\
\hline Carbon aerogels & $\mathrm{C}_{3} \mathrm{H}_{8} \mathrm{~N}_{2} \mathrm{O}$ & 300 & 0.24 & $99 \%$ & - & - & [38] \\
\hline Carbon aerogels & $\mathrm{C}_{2} \mathrm{H}_{3} \mathrm{Cl}$ & 1600 & - & $98 \%$ & $2 \mathrm{~nm}$ & - & [39] \\
\hline Silver aerogels & $\mathrm{AgNO}_{3}$ & 400 & 27 & $98 \%$ & $10-100 \mathrm{~nm}$ & - & [40] \\
\hline Zinc aerogels & $\mathrm{ZnC}_{4} \mathrm{H}_{6} \mathrm{O}_{4}$ & 350 & - & $99 \%$ & - & - & [41] \\
\hline Titanium aerogels & $\mathrm{C}_{16} \mathrm{H}_{36} \mathrm{O}_{4} \mathrm{Ti}$ & 300 & - & $98 \%$ & 20 & - & [42] \\
\hline Cellulose aerogels & Wood & - & - & $98 \%$ & - & - & [43] \\
\hline Chitosan aerogels & Chitosan powder & 400 & - & $99 \%$ & - & - & [44] \\
\hline Biomass aerogels & Konjac glucomannan & - & 47 & $95 \%$ & - & - & [45] \\
\hline
\end{tabular}

It is revealed from Table 1 that most of the structural characteristics primarily depend on synthesis route and type of precursor used. Silica aerogels are synthesized at the earliest and classified as inorganic aerogels. Silica aerogels are widely studied due to their facile synthesis and commercial development and are considered as a standard form of aerogels for comparison with newly developed aerogels. The synthesis process of silica aerogels consists of the following steps: silica gel is prepared as a first step and then the 
gel is processed for aging and drying. Ambient drying and supercritical drying processes are mostly followed during the synthesis of aerogels. However, the lateral method is challenging due to hazards and high cost in perceiving the large-scale production of aerogels. In a previous study, Maleki et al. reviewed the synthesis of silica aerogels with different methods and stated that ambient drying is a facile and cost-effective method to synthesize the composites of aerogels. In addition, post gelation and high pressure makes ambient drying more suitable for the bulk production of aerogels [46].

Another important type of aerogels is metal-based aerogels that are indispensable for their excellent electrical conduction properties. Metallic aerogels have gained intense attention in recent years due to their higher surface area and ultralow densities. Researchers worked with various type of metals, i.e., gold, silver, copper, titanium, zinc, nickel, cobalt and successfully fabricated metal aerogels with tunable surfaces, structural and electrical properties [47-50]. In an experimental study, Qian et al. reported the synthesis of ultralight gold aerogel monoliths with tunable pore densities and structures. Different solvents and their suspension are crucial parameters for the systematic tuning of monolithic gold aerogels with enhanced densities and pore architectures [51]. In a previous study, Qian et al. synthesized ultralight silver aerogel monoliths with excellent conduction properties and tunable densities via silver nanowires. Silver nanowires were used as building blocks, and the freeze-casting method followed by sintering was used as the fabrication route for silver aerogel monoliths [52]. Yan et al. reported a three-dimensional printing technique and freeze casting method for the fabrication of metallic aerogels. The results demonstrated that by using these techniques, the densities are controllable and high electrical conductivity is achieved [53]. In a different study, $\mathrm{Xu}$ et al. fabricated ultralight flexible pressure sensors with the help of copper nanowires. Copper nanowires were assembled into copper aerogels via the one-pot method. The fabricated pressure sensors demonstrated excellent results for sensitivity, tunable pore architecture and ultralow density [54].

The cost and properties of silica aerogels mainly depend on the fabrication methods. The precursors mainly used for the synthesis of silica aerogels are sodium silicate and various types of silanes, e.g., tetramethoxysilane, tetraethoxysilane and polyethoxydisiloxane. Due to their hazardous effects and higher cost, silanes are not commercially used for the fabrication of silica aerogels. However, for bulk production and cost effectiveness, sodium silicate is utilized as a cheaper precursor for the synthesis of silica aerogels [55]. In a previous study, Carlson et al. reported that the synthesis of silica aerogels with sodium silicate precursor is 7.7-13.5 times more cheaper than silanes precursors [56]. We came to know that silica aerogels are brittle in nature and additives (polyethylene glycol) play an essential role for maintaining the pore volume size and mechanical properties. The addition of polyethylene glycol in the synthesis of aerogels control the strength of solution matrix, which means a lower concentration of polyethylene glycol strengthens the solution matrix and vice versa. In addition, the concentration of hydrophilic and water-soluble polymers adjusts the pore size of silica aerogels.

Due to their remarkable properties and structure, graphene oxide (GO) has been investigated and used in the synthesis of aerogels. GO improves the porosity during the interaction with silica matrix, restricts the transfer of heat and enhances the thermal properties 1.5 times more than pure silica aerogels. In addition, GO enhances the mechanical properties besides the augmentation in the thermal stability of the composite [57]. Lei et al. worked with silica aerogels and added GO as a nanofiller during the synthesis of $\mathrm{GO} / \mathrm{SiO}_{2}$ composites aerogels. They reported that GO improves the thermal insulation and mechanical properties of the aerogels. The positive influence of GO was due to the homogenous distribution of GO inside the silica matrix and the interfacial interaction between silica and GO nanosheets [58].

In a similar manner, the inclusion of fibrous material during the synthesis of aerogels enhances the thermal and mechanical properties. Patil et al. investigated the effect of carbon nanotubes, glass fibers and graphene nanosheets during the synthesis of silica aerogels and compared the results with virgin silica aerogels. The results revealed that 
aerogels composed of carbon nanotubes, glass fibers and graphene nanosheets demonstrate significant augmentation in tensile strength by nine, three and eight times and $11.5,3.5$ and 9.5 times augmentation in elastic modulus than standard silica aerogels, respectively [59]. Li et al. conducted many studies on silica aerogels composed of aramid fibers to enhance thermal and mechanical properties. The results revealed that silica aerogels with aramid fibers possess lower bending modulus with exceptional flexibility. The compressive strength increased up to $1.2 \mathrm{MPa}$ with extremely low thermal conductivity $0.0227 \pm 0.0007 \mathrm{~W} \cdot \mathrm{m}^{-1} \cdot \mathrm{K}^{-1}[60,61]$.

We came to know a fact through literature review that silica aerogels are mostly used as commercial thermal insulating materials due to their economic raw materials and facile drying process. The ambient drying process is mostly used for the commercial production of silica aerogels due to its economic benefits. In general, aerogels are extremely high thermally insulating materials with poor mechanical properties that may be improved or adjusted by the inclusion of different additives, i.e., fibrous materials, carbon nanotubes and graphene, during the synthesis mechanism.

\section{Applications of Aerogels}

Aerogels are special materials that have an enormous diversity of outstanding physicochemical properties, including mechanical, physical and chemical properties, and therefore many applications have developed with aerogel utilization. Some of the most sensitive applications are catalysis, thermal insulation, electrodes, solar thermal energy systems, waste engine oil, oil spill cleaning, drug and protein delivery, medical implantable devices and supercapacitors. This section presents the recent advanced technical applications of aerogels in different fields, including biomedical engineering, energy, environment and sensors.

\subsection{Aerogels for Biomedical Engineering}

Aerogel materials has proven potential applications in biomedicines and attracted great attention in recent years. Aerogels have been applied in different applications, such as tissue engineering, drug and protein delivery, implantable medical devices, bone grafting, biosensing and blood sorption [62-64]. This section introduces various recent applications of aerogels in biomedical engineering.

Aerogel has been widely used in tissue engineering for the regeneration of different types of tissues, such as bones, skin, blood vessels, and cartilages. Muñoz-Ruíz et al. proposed and evaluated the collagen-alginates aerogel for the regeneration of different tissues using bio-based materials, in order to solve the problem of the potential complications related to autografts. The results revealed that the induced properties after drying are responsible for these changes. The aerogel microstructure was very stable and composed of highly porous 3D interconnected networks that helps in cell attachment [65]. Osorio et al. modified cellulose nanocrystal aerogels and used them as viable bone tissue scaffolds. The experimental results demonstrated that cellulose-based aerogels are porous and flexible and facilitate bone growth after their implant in bone defects. In addition, the aerogels demonstrated an increase in cell metabolism [66]. Reyes-Peces et al. presented a hybrid aerogel structure composed of chitosan and silica for bone tissue engineering. They synthesized the hybrid aerogels by the sol-gel method followed by supercritical $\mathrm{CO}_{2}$ drying. They used glycidoxypropyl trimethoxysilane (GPTMS) as the crosslinking or coupling agent, and tetraethylortosilicate (TEOS) as silica precursor. The results of in vitro study demonstrated that the proposed hybrid chitosan silica aerogel composite structure provides a durable substitute in bone tissue engineering for cells recruitment and maturation by inducing an excellent osteoblast response [67]. Groult et al. investigated the influence of the drying process on the structural and release properties of pectin hydrogels, aerogels, cryogels and xerogels. They prepared the porous pectin aerogels, xerogels and cryogels using super critical drying, freeze-drying and evaporative drying under low vacuum. They investigated and compared the kinetics of drug release from all the mentioned materials, 
including hydrogel. Scanning electron microscopy (SEM) images illustrate that the drying method has a noteworthy influence on different properties of the pectin networks, as shown in Figure 2. Shrinkage was observed for pectin cryogels that might originate upon immersion of the sample into nitrogen for the freezing of water prior to sublimation. Due to this, samples made with the freeze-drying method display very low density. Figure 3 shows the experimental samples with the dry core in pectin aerogels, which confirm the slow solvent transport through the dry system, in contrast with the pectin hydrogels and cryogels [68].
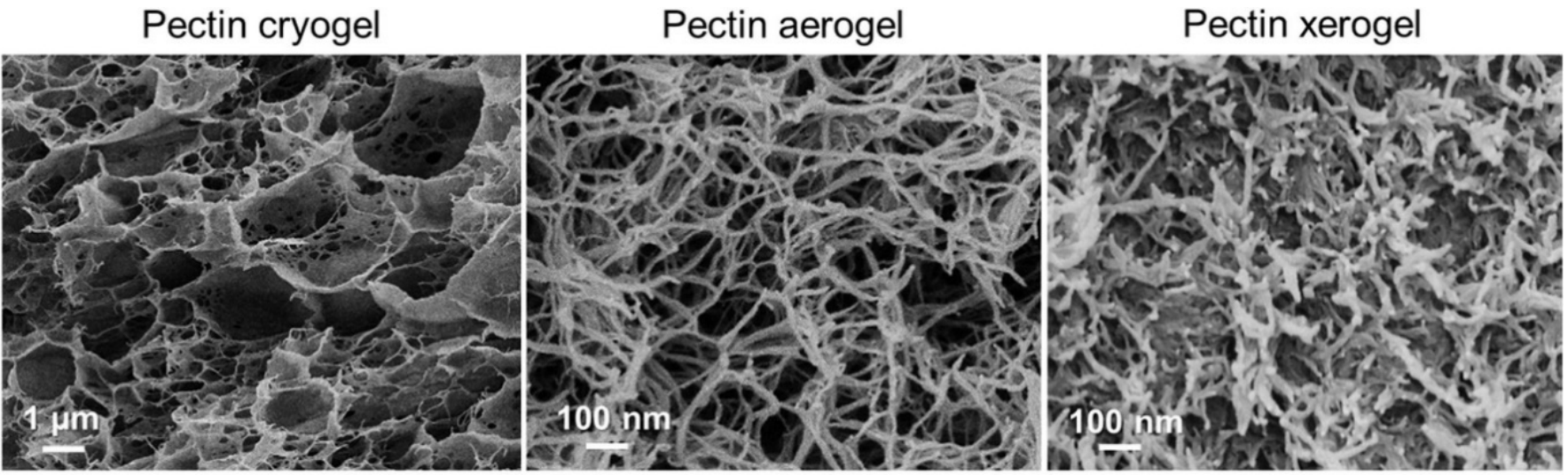

Figure 2. SEM micrographs of pectin cryogels, aerogels and xerogels. Reprinted with permission from [68].

\section{Hydrogel}

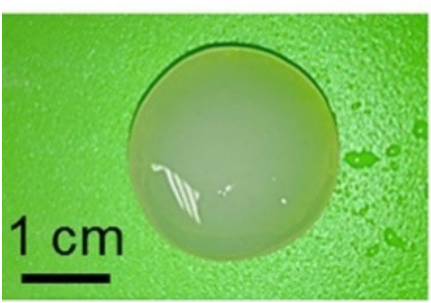

Cryogel

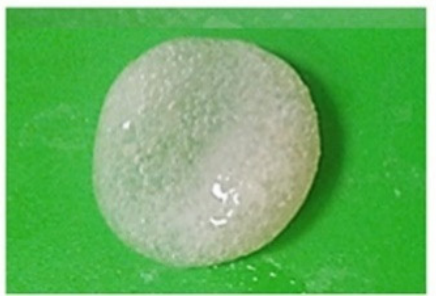

Aerogel

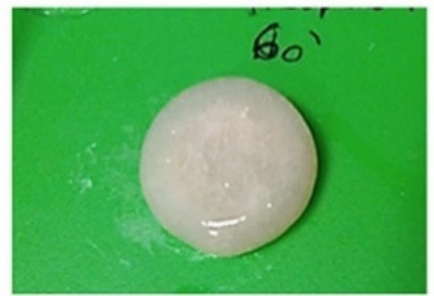

Xerogel

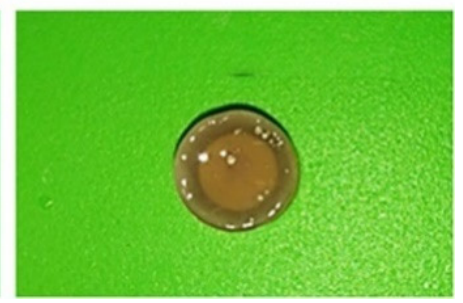

Figure 3. Practical samples of a pectin hydrogel, cryogel, aerogel and xerogel. Reprinted with permission from [68].

Rostamitabar et al. produced cellulose aerogel fibers under the super critical $\mathrm{CO}_{2}$ drying method and tested their samples on the drug model. The surface morphology and structural properties of the synthesized aerogels were characterized by different spectroscopies. In addition, thermal stability, mechanical properties and drug release assessments were also performed. The results revealed that fibrous structures were able to absorb excessive amount of moisture and due to their open porous structure, aerogels released the drug immediately and demonstrated non-toxic behavior [69]. In another study, Marco et al. produced polysaccharide-based aerogels, which were further used as carriers for drug delivery systems. They analyzed their samples on the basis of the life cycle assessment and from an environmental point of view to minimize total emissions. Aerogels of starch were synthesized under the following three steps: (1) Prepare the gel using an aqueous solution; (2) replace the water by alcohol to develop alcogels; (3) use of the super critical $\mathrm{CO}_{2}$ drying process to obtain bio aerogels. The experimental results demonstrated that the carcinogens and mineral extraction were mainly the affected categories as a consequence of the high energy consumption in the drying step; in addition, the respiratory organics were infected due to the ethanol used in the alcogel formation [70].

Recently, Saadatnia et al. developed conductive aerogel films for the monitoring of electrophysiological properties and proposed a novel model of wet electrode. The electrodes were composed of cellulose nanocrystals and multi-walled carbon nanotube. Cellulose nanocrystals were used as biopolymers and carbon nanotubes as conductive 
fillers. The produced electrode is featured to investigate the electrical, chemical, water absorption and mechanical properties. The fabricated model has very high performance, which makes it effective for wet electrode applications, thanks to the high percentage of water absorption due to its hydrophilicity and porosity. In addition, the proposed model guarantees the multiple use of a fabricated electrode for different applications, such as remote and long-term monitoring of patients, and for different electrophysiological monitoring devices, e.g., electroencephalography (EEG) and electrocardiography (ECG) [71]. In another study, Tetik et al. synthesized cellulose-based aerogels with excellent 3D geometries and shapes with overhang properties. They determined the impact of the used method for the improvement of the mechanical properties of synthesized aerogels. In addition, they evaluated the bonding strength to augment the stability of aerogels in order to make them feasible for tissue engineering and biomedical applications. Figure 4 shows the essential steps involved in the making of aerogels used in materials and methods as well as the results of SEM observations [72].

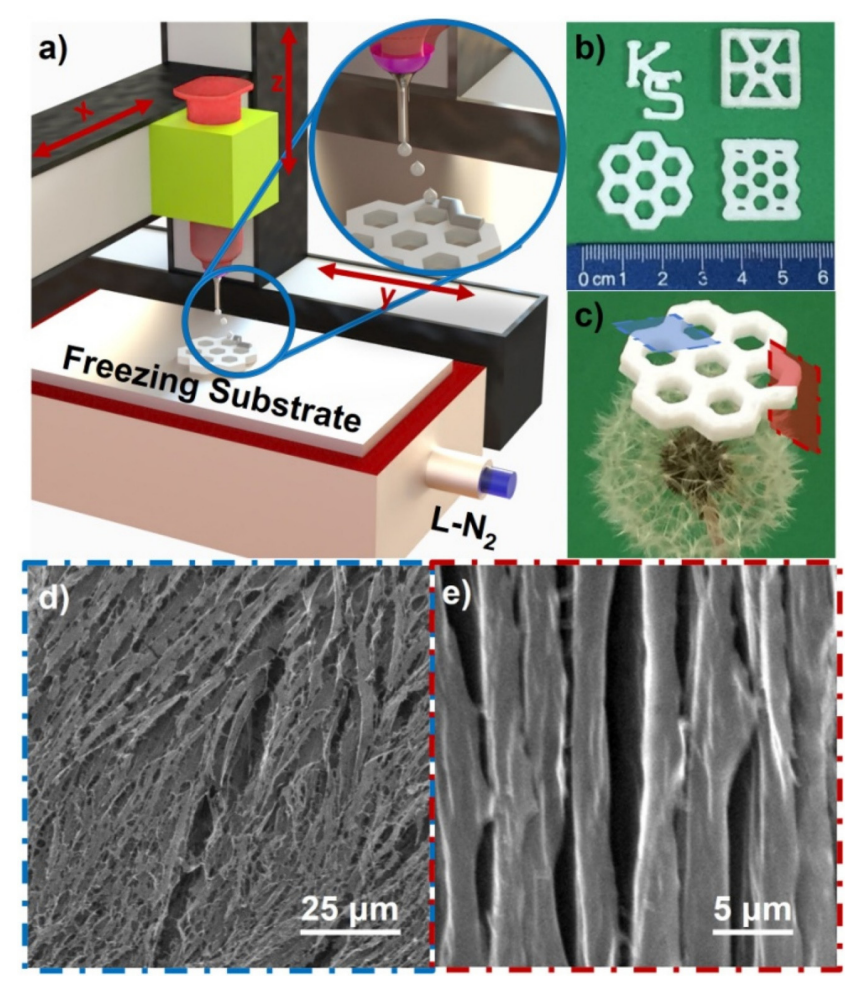

Figure 4. (a) A schematic illustration of 3D freeze-printing process. (b) Different geometries of 3D cellulose aerogels. (c) Cellulose aerogel with honeycomb shape standing on a dandelion. (d) SEM micrograph displaying the top surface of 3D freeze-printed aerogel. (e) SEM micrograph displaying the cross-sectional surface of 3D freeze-printed aerogel. Reprinted with permission from [72].

\subsection{Aerogels for Energy}

Aerogels have the advantages of biodegradability and low density that make them a good choice for solving serious environmental problems. Researchers have proposed and developed many techniques that produce green and sustainable electrodes, based on aerogels, as a solution for pollution and other environmental concerns [73-75]. In an experimental study, Strobach et al. reported the synthesis of optically transparent and thermally insulating monolithic silica aerogels with high solar transparency, especially developed for the solar thermal receiver. They elaborated the effects of annealing at different annealing temperatures. They explained that the structures and properties of aerogels could be controlled by controlling the temperature. In addition, the time and temperature of annealing were helpful in the optimization of aerogels for better optical 
and thermal properties. The results elucidated good prediction performance of aerogels in solar thermal applications [76].

Li et al. introduced a modified evacuated receiver with solar transparent aerogels in order to improve the receiver performance. In addition, they developed and validated an optical-thermal model for modeling the energy transfer in the collector. Figure 5 exhibits the traditional evacuated receiver that was chosen as a standard model and the modified receiver that was designed with the addition of aerogels at an angle of $120^{\circ}$ at a directly illuminated region. The results revealed that the effects of aerogels on the modified receiver are significant. Aerogels coating's emittance greatly affects the receiver performance. The optimal efficiency was achieved by adding aerogels with opaque insulation [77].

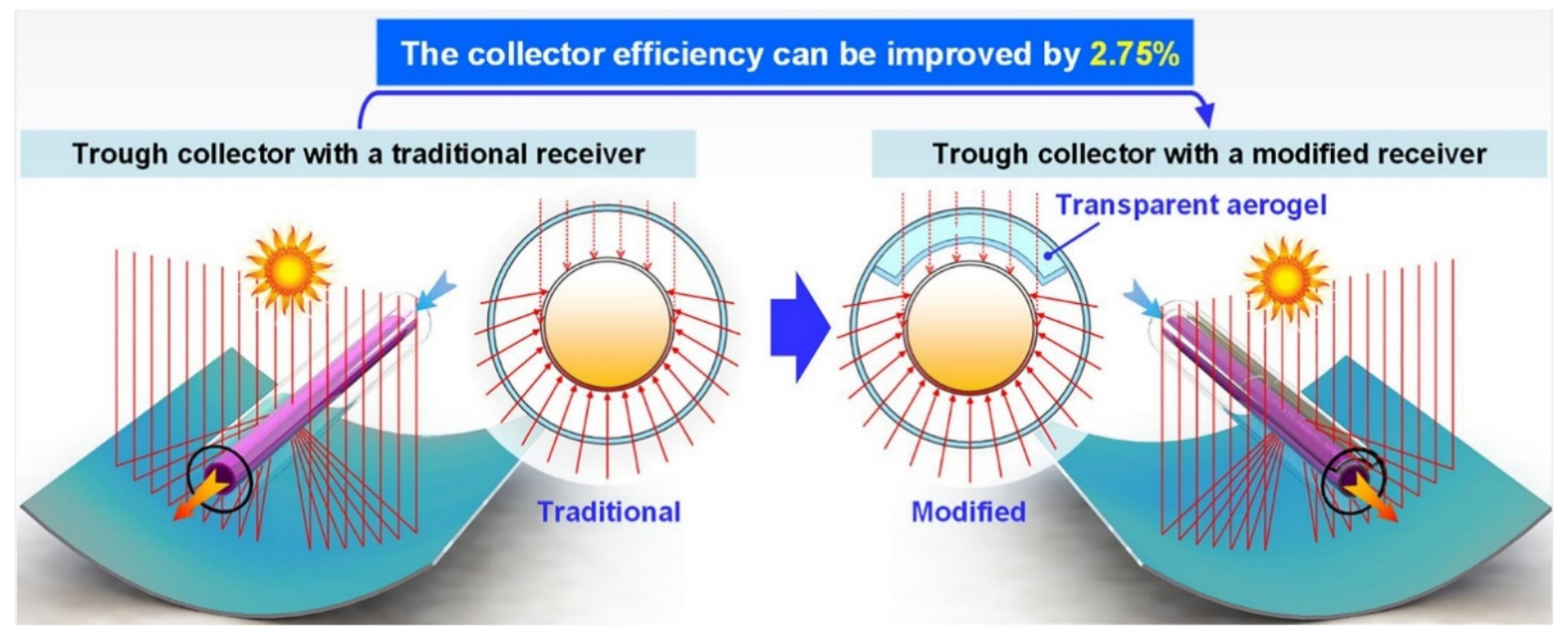

Figure 5. Traditional evacuated receiver and evacuated receiver modified by aerogels. Reprinted with permission from [77].

Recently, Han et al. prepared thermally insulated aerogels using $\mathrm{TiO}_{2}$ and chitosan under combined thermal reduction and freeze-casting methods. Experimental results demonstrated that the produced aerogels have excellent mechanical properties, thermal insulation behavior and good high-temperature service performance [78]. Lui et al. synthesized novel and homogeneous $\mathrm{TiO}_{2} / \mathrm{SiO}_{2}$ aerogel composites with synchronous sol-gel method. The proposed technique provides hydrophobic properties achieved by pre-heat treatment and surface modification. The thermal conductivity test, structure characterization, energy saving simulation calculation and infrared radiation heat transfer calculation of $\mathrm{TiO}_{2} / \mathrm{SiO}_{2}$ aerogel composite were executed. Therefore, the thermally insulated properties for steam pipe application that works for high temperatures were obtained accordingly. The obtained results of $\mathrm{TiO}_{2} / \mathrm{SiO}_{2}$ aerogel composite were compared with hybrid glass fiber $/ \mathrm{SiO}_{2}$ composites. The results demonstrated that glass fiber $/ \mathrm{TiO}_{2} / \mathrm{SiO}_{2}$ aerogel composite had better results for thermal conductivity than others. The energy-saving effect of the glass fiber $/ \mathrm{TiO}_{2} / \mathrm{SiO}_{2}$ aerogel composite demonstrated excellent performance in saving oil consumption silica aerogels [79].

The role of aerogels for energy applications, especially supercapacitors and batteries, has been increasing day by day. Long et al. introduced a novel method for the fabrication of $\mathrm{N}_{2}$ doped carbon aerogels for supercapacitors. They prepared the biomass-derived carbon aerogel using glucose, cellulose nanofibers and dicyandiamide as precursors. The multifunctional materials were validated on flexible electronics, sensors and energy storage/conversion devices, i.e., supercapacitors, where they demonstrated excellent thermal and mechanical properties [80]. In another study, Lui et al. reported the synthesis of tungsten oxide $\left(\mathrm{WO}_{3}\right)$ nanoparticles and their homogenous dispersion and deposition on carbon-based aerogels for the development of supercapacitors. Experimental results demonstrated that the addition of $\mathrm{WO}_{3}$ nanoparticles enhances the capacitance with a 
reduction in size and provides an exponential increase for capacitance values; however, during cycling, carbon aerogels facilitate charge transfer. The proposed method achieved a high value of capacitance in comparison with other kinds of nanomaterials deposited on carbon aerogels for supercapacitor applications [81]. Carbon-based aerogels are generally famous for lightweight and long-lasting batteries with excellent charge/discharge capabilities. Muniyandi et al. worked with carbon-based hybrid aerogels for high performance lithium-ion batteries. They successfully synthesized $\mathrm{Li}_{2} \mathrm{FeSiO}_{4} / \mathrm{C}$ aerogels with sol-gel method and supercritical drying. The electrode kinetics and storage performance of the synthesized aerogels were characterized by electrochemical impedance spectroscopy, cyclic voltammetry and galvanostatic charge discharge methods. The results demonstrated that the fabricated electrode delivers $140 \mathrm{~mA} \cdot \mathrm{h} \cdot \mathrm{g}^{-1}$ discharge capacity for 130 cycles [82]. In another experimental study, Chen et al. incorporated $\mathrm{Fe}_{3} \mathrm{O}_{4}$ nanoparticles during the synthesis of carbon nanotubes aerogels that significantly enhanced the electron transport, ion diffusion and reduced volume expansion of lithium-ion batteries. Moreover, the results demonstrated that the fabricated anode delivers extraordinary charge/discharge (reversible) capacity after 100 cycles [83]. Jiang et al. worked with boron nitride nanomaterial-based aerogel composites to achieve low thermal conductivity. They reported the fabrication of aerogelbased thermoelectric batteries with excellent durability, no maintenance, long life and high reliability [84]. Some other applications of aerogels are in the form of catalysts, construction and building materials that possess the potential for environmental remediations [85-89]. Golder et al. reported the significance of aerogels in the development of insulating materials for construction and buildings. They deposited translucent aerogel glazing systems in the walls and windows of different buildings for better insulation performance. The results demonstrated that the deposition of aerogels in the wall and window insulation and glazing systems has significant potential to reduce energy consumption and cost of buildings [90]. Qi et al. reported the tribology behavior of silica aerogels reinforced with polybutylene terephthalate for a deep-sea environment. They evaluated the tribological properties, thermal and mechanical properties, absorption of binary nanocomposites and seawater wettability. Their results demonstrated that the incorporation of silica aerogels increase the wear-resistance, seawater repellency and thermal stability. However, they decrease the acceleration of seawater absorption, mechanical strengths and wear rate of polybutylene terephthalate. A schematic diagram of silica aerogels for sea environment is illustrated in Figure 6 [91].

(a) Structure of $\mathrm{SiO}_{2}$ aerogel

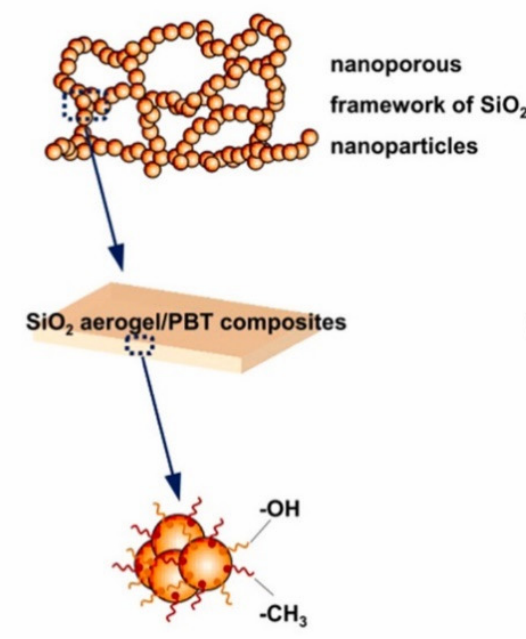

(b) Influence of $\mathrm{SiO}_{2}$ aerogel content

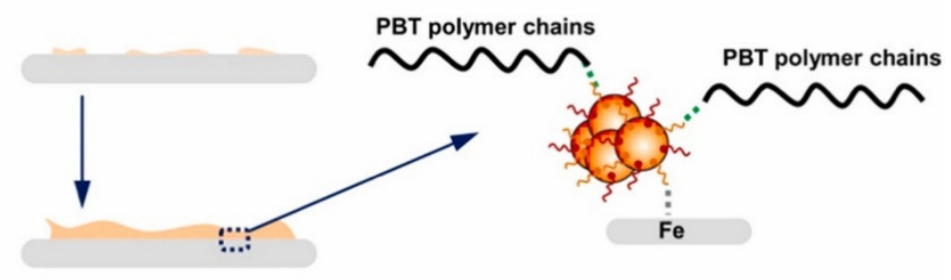

(c) Influence of seawater pressure

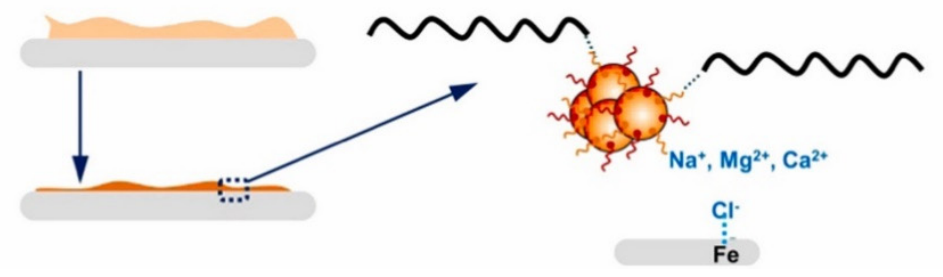

Figure 6. Application of silica aerogels in sea water, (a) structural evolution of silica aerogels, (b) the influence of silica content, (c) seawater pressure on silica aerogels and poly butylene terephthalate composites. Reprinted with permission from [91]. 


\subsection{Aerogels for Sensors}

Aerogels and aerogel-based composite materials have strong mechanical strength, excellent flexibility, high porosity, lightweight and excellent durability. These characteristics attract the researchers interests and fulfill the requirements for the fabrication of various types of sensors, e.g., gas sensors, electrochemical sensors, pressure sensors, humidity sensors, flexible sensors and tactile sensors. With the advancement in science and research, gas sensors have achieved significant importance in many fields for the detection of explosive and toxic gases as well as the gases for disease diagnosis [92,93]. Resistive types of gas sensors are mostly used due to their facile fabrication, low cost and easy operation. In resistive sensors, the sensing operation takes place on the surface of the active sensing material and the conductivity changes during the absorption of the gas molecules on the surface of the active sensing layer. Aerogel-based sensors have two major advantages, i.e., first, a high specific surface area and surface-to-volume ratio that provides sufficient surfaces for the adsorption of gas molecules; second, a 3D porous interconnected structural network that provides a stable and fast transport channel for the diffusion of gas molecules. Thus, aerogel-based sensors demonstrate fast recovery rate, low detection limit, high sensitivity and fast response rate. Table 2 shows some recent work on aerogel-based gas sensors.

Table 2. Aerogel-based sensors and their performance.

\begin{tabular}{|c|c|c|c|c|c|}
\hline Aerogel Type & Analyte & Response/Recovery Rate & Sensing Range & Detection Limit & References \\
\hline Graphene aerogel & Ammonia & $100 \mathrm{~s} / 500 \mathrm{~s}$ & $0.02-85 \mathrm{ppm}$ & $10 \mathrm{ppb}$ & [94] \\
\hline Carbon aerogel & $\begin{array}{l}\text { Toluene and } \\
\text { n-hexane }\end{array}$ & $25 \mathrm{~s} / 20 \mathrm{~s}$ & - & - & [95] \\
\hline Graphene aerogel & $\mathrm{NO}_{2}$ & $116 \mathrm{~s} / 169 \mathrm{~s}$ & $0.1-1 \mathrm{ppm}$ & $50 \mathrm{ppb}$ & [96] \\
\hline $\mathrm{TiO}_{2} / \mathrm{SiO}_{2}$ aerogels & $\mathrm{H}_{2} \mathrm{~S}$ & $53 \mathrm{~s} / 74 \mathrm{~s}$ & $0.5-50 \mathrm{ppm}$ & $0.5 \mathrm{ppm}$ & [97] \\
\hline $\mathrm{ZnO}$ /graphene aerogels & $\mathrm{NO}_{2}$ & $132 \mathrm{~s} / 164 \mathrm{~s}$ & 10-200 ppm & $10 \mathrm{ppm}$ & [98] \\
\hline $\begin{array}{c}\text { Silica aerogels/ Carbon } \\
\text { quantum dots }\end{array}$ & $\mathrm{NO}_{2}$ & - & $2-10 \mathrm{ppm}$ & $250 \mathrm{ppb}$ & [99] \\
\hline Silica aerogel film & Humidity & $38 \mathrm{~s} / 21 \mathrm{~s}$ & $20-90 \%$ RH & - & [100] \\
\hline
\end{tabular}

Alizadeh et al. reported the fabrication of an ammonia gas sensor with the help of graphene hydrogels characterized with ppb level determination capability. They followed the hydrothermal method for the synthesis of 3D graphene aerogels. The mechanism of sensing was related to the variation in electrical resistance. The fabricated device was highly efficient and capable of sensing ammonia gas in a reversible manner at ambient temperature under a short span of time [101]. Gao et al. fabricated gas sensors based on zinc oxide and reduced the graphene oxide aerogel composites for the detection of nitrogen dioxide $\left(\mathrm{NO}_{2}\right)$. The obtained results reveal that after the freeze-drying method, aerogels have a regular cylindrical shape with larger pore sizes; however, zinc oxide was homogenously distributed on the surface of graphene oxide and provides a solid network of crosslinking. In addition, the results demonstrated that the fabricated sensor provides a quick response for $\mathrm{NO}_{2}$ detection with a fast recovery rate and good reproducibility [102]. Bibi et al. reported the fabrication of carbon aerogels and polyaniline-based gas sensor for the detection of hydrogen sulphide $\left(\mathrm{H}_{2} \mathrm{~S}\right)$ gas. They explained that aerogel-based composites were first applied on the interdigitated electrode made of glass. Carbon aerogels were dispersed with the spin-coating method on the electrode for gas sensing [103].

The pressure and strain sensors convert the applied pressure change and deformation into the electricity of an object. These sensors have demonstrated their potential in different fields, especially in wearable health monitoring devices and artificial skins. The sensing mechanisms of any pressure and strain sensor are based on piezo resistivity, capacitance and piezoelectricity. Piezoresistive pressure and strain sensors are the most promising sensors, among other types of pressure sensors, and they are widely studied due to their 
facile read-out system and easy structures. In addition, the aerogel-based piezoresistive pressure and strain sensors have enough tolerance for large deformation and high elasticity; therefore, they provide a large sensing range. In an experimental study, Zhu et al. prepared a sensitive piezoresistive sensor, based on reduced graphene oxide and carbon nanotube aerogels, by using a hydrothermal redox method for human motion detection. Furthermore, they proposed that the fabricated sensor provided good stability, fast response time, high sensitivity and a wide working range [104]. Cao et al. reported the synthesis of polyacrylonitrile nanofiber-reinforced graphene aerogels for piezoresistive-sensing applications. In this method, nanofibers worked as scaffolds for the graphene network and provide a $3 \mathrm{D}$ interconnected hierarchical microstructure. The results demonstrated excellent compression resilience, fast response time, perfect sensing durability and structural stability. Furthermore, the fabricated sensors were able to evaluate real time movements of the wrist, fingers, wrist pulse and knee joints at a good sensitivity [105]. Wei et al. reported the fabrication of the pressure sensor based on graphene/biomass hybrid aerogels. A facile and green strategy was used to fabricate these types of sensors by the effective reduction of graphene oxide through bacteria cellulose and caffeic acid. The fabricated sensor demonstrate fast response, high sensitivity and excellent reproducibility. Sensors exhibit an integrated performance of ultralow limit of detection, high sensitivity and fast responses, and clearly detect the subtle strain and monitor physical human motions. Figure 7 shows the application of fabricated sensors during the capturing of human motion [106].
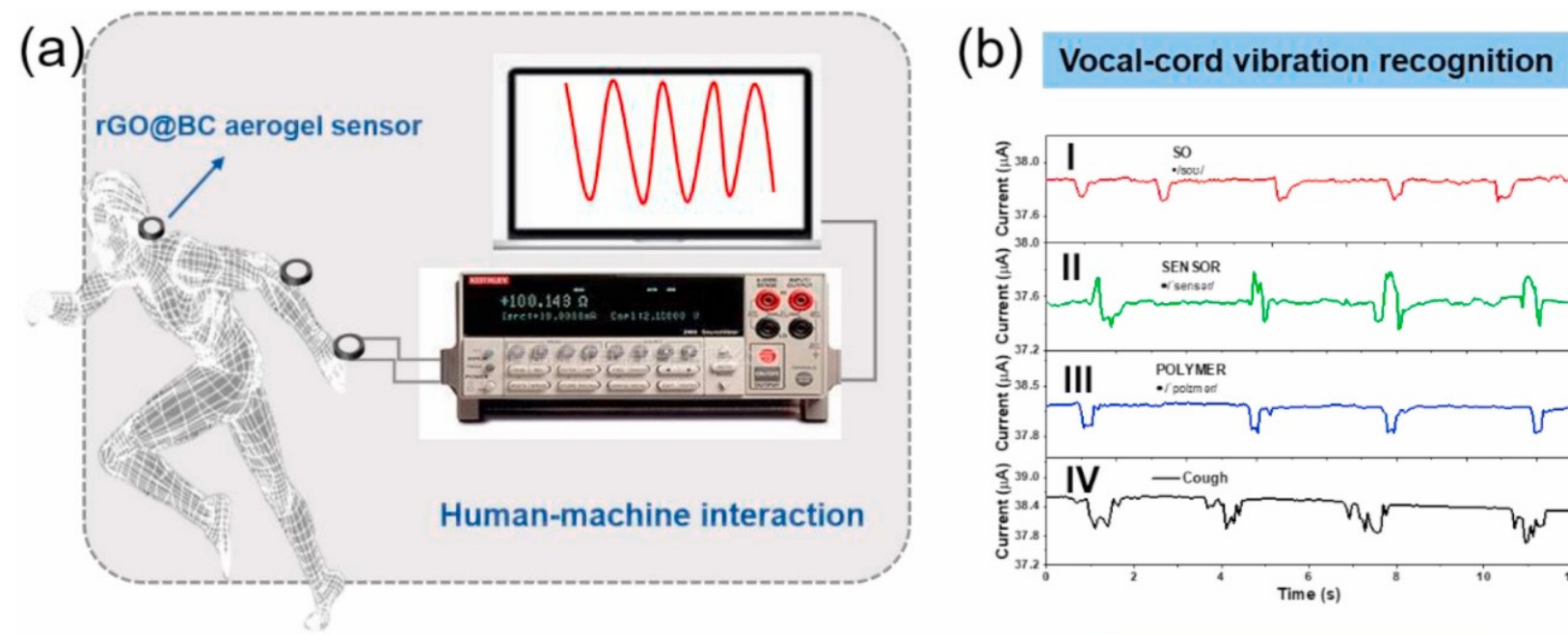

(c)
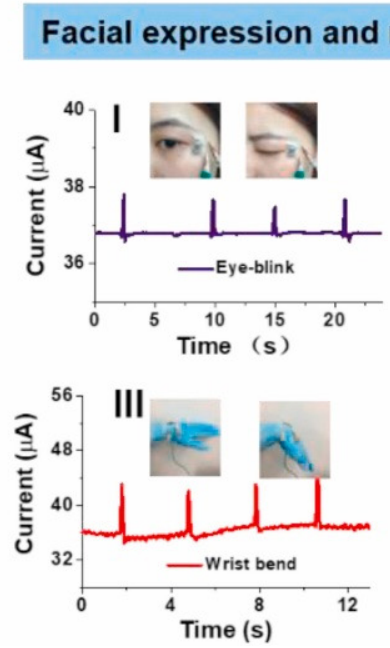

II

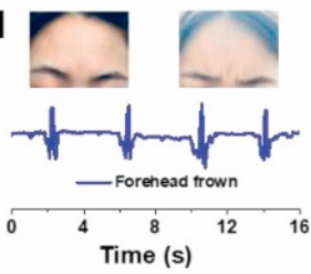

IV

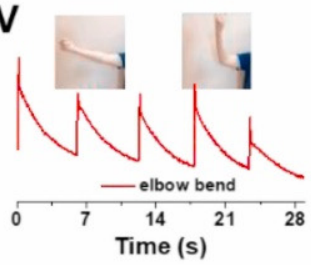

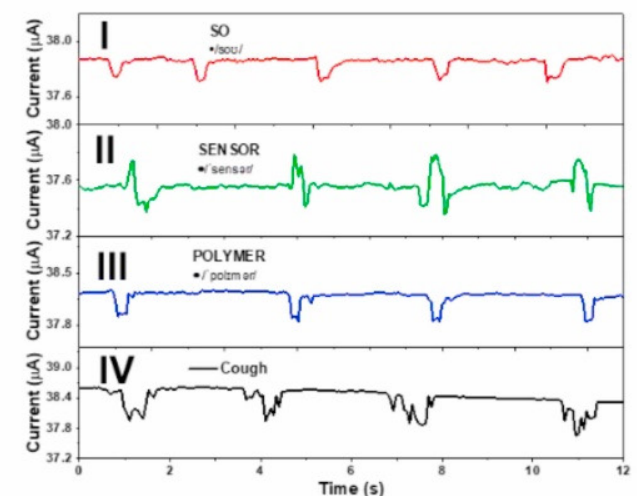

(d)

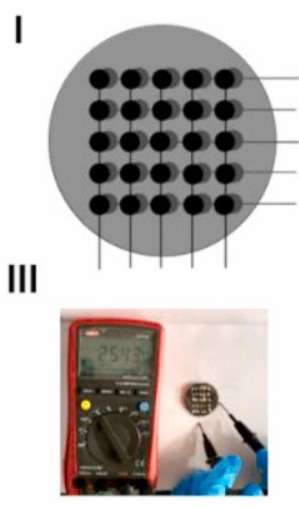

\section{Artificial electronic skin}

II
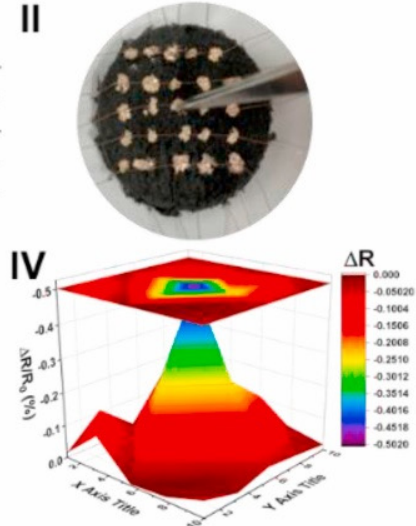

Figure 7. (a) Illustration of reduced graphene oxide-based aerogel-sensing platform, (b) Vocal-cord vibration recognition, (c) facial expression and body movement monitoring, and (d) aerogel-based artificial skin. Reprinted with permission from [106]. 
Carbon-based aerogels are widely studied for their electrical properties, good compressibility and high porosity as piezoresistive sensors. Bi et al. reported the fabrication of electrodes made of carbon aerogels clustered on a carbon ball. The main purpose of the proposed technique is to develop a electrochemical sensor from the biomass of taros. The results demonstrated a high electrochemical activity performance and the proposed method revealed its potential as a powerful electrode for the fabrication of multi-functional electrochemical sensors for practical applications [107]. Yang et al. fabricated superhydrophobic and conductive aerogels with honeycomb-like microstructures under directional freezedrying methods for the piezoresistive pressure sensor. The fabricated sensor provides a wide detection range, excellent electrical repeatability, stability and fast respond times. The fabricated sensor was used to evaluate the motion of the human body, where it demonstrated stable work under humid or sweaty environments. In addition, the fabricated sensor detected real-time movements of finger joints, as illustrated in Figure 8 [108].

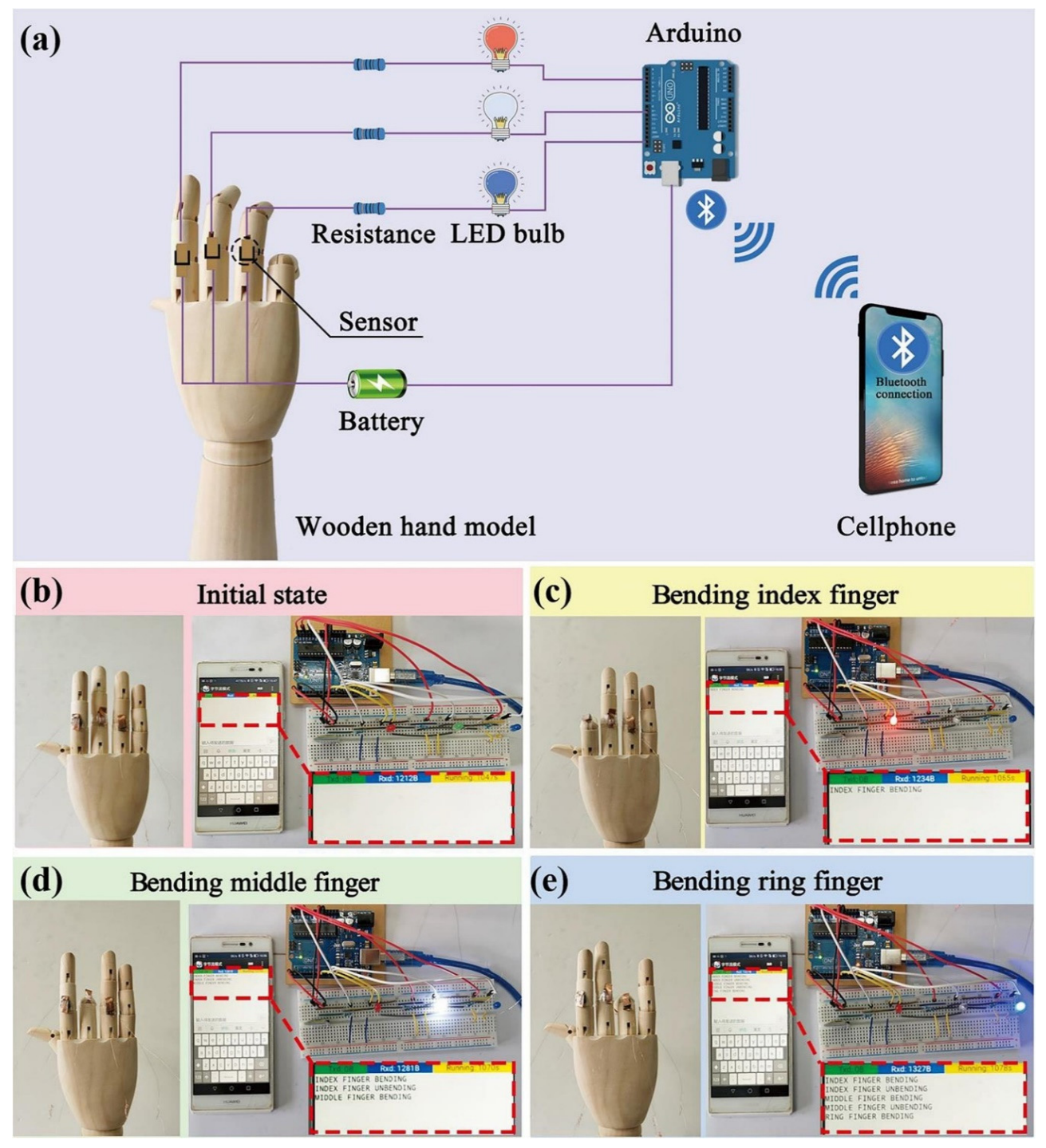

Figure 8. (a) Illustration of Arduino microcontroller connected to a circuit for finger movement detection, sending messages to a cellphone through Bluetooth connection. Photographs of the wooden hand model (b) in the initial state, (c) bending index finger, (d) bending middle finger, (e) bending ring finger and the corresponding photographs of the cellphone displaying messages from Arduino microcontroller and LED bulbs emitting red, white and blue lights, respectively. Reprinted with permission from [108]. 


\section{Summary and Future Direction}

- In this study, a brief history and the applications of aerogels based on their classification and synthesis methods are reviewed and discussed. Aerogels are considered as excellent candidates for biomedical, energy, environment and sensing applications, and especially for high-performance sensors, where high sensitivity is required. Due to their structural characteristics and other properties, including having a highly porous structure, high specific surface area and other specific features provided by the aerogel network, aerogels are suitable for many applications. Therefore, based on the discussion, it is concluded that the combination of low dimensional active building blocks induces fascinating properties in the resulting aerogels, which display satisfactory performances in multiple applications. However, there are many challenges that still need to be addressed.

- The economic and bulk production of high-quality aerogels is still a major issue that needs to be solved. Efforts have been made to simplify the synthesis mechanism in order to scale up and to reduce cost. Therefore, freeze drying (lyophilization), modified super critical drying and ambient drying methods were used. However, during the drying conditions, it was not easy to completely maintain the microstructure of the gel, therefore, damage frequently occurred.

- Surface modification techniques employed for ambient drying inevitably causes a negative effect on the performance of aerogels. The overall properties of aerogels become disturbed during surface modification. The discussed studies demonstrate the superiority of aerogels in comparison with powdered materials in different fields. Therefore, aerogels with no structural variation own superior properties and a largescale production of low-cost aerogels with superior qualities is vital and should be realized.

* Maintain the porosity of the structure, especially the microporosity of the aerogel structure under stress during the fabrication of aerogel products, i.e., biosensors, gas sensors, ion batteries and catalysts. During the fabrication of sensors, aerogels are dispersed in solvents in order to get a uniform dispersion and coated on other substrates to make aerogel-based sensors. During this dispersion process, the microporous structures of aerogels are deteriorated and a decrease in mass and energy transfer is observed in the resultant sensor. However, in a comparison, these sensors still behave better and display a much-increased sensing performance than powder-based sensors. It is still believed that if the intrinsic porosity of the aerogel structures is retained well during the fabrication of sensors, the performance of the aerogel-based sensor can further be improved.

* The utilization of thin aerogel films covers the microporous structural damage caused during the synthesis of sensors. Aerogels with excellent mechanical features are the prerequisites for the synthesis of aerogel films. Therefore, the mechanical properties of various types of aerogels, e.g., organic, inorganic and hybrid, should be improved. In this matter, the inclusion of additives (supporting materials) is considered a facile way to increase the overall mechanical properties. Although, when the mechanical properties are enhanced and the structure of aerogel is controlled, the extension of this technique remains a challenge for all kinds of aerogels. Therefore, it is compulsory to develop a common method that works for all types of aerogels to enhance their mechanical properties.

Author Contributions: Conceptualization, M.T.N. and N.A.; Methodology, M.T.N., N.A. and K.A.; Software, M.T.N., A.A. and M.F.; Validation, M.T.N., R.C. and S.P.; Formal analysis, M.T.N., K.A., A.A., N.A. and M.F.; Investigation, M.T.N., N.A., K.A., R.C. and M.F.; Resources, M.T.N., K.A. and S.P.; Writing-original draft preparation, M.T.N. and N.A.; Writing-review and editing, M.T.N., N.A., K.A., R.C., S.P. and M.F.; Supervision, S.P.; Project administration, S.P.; Funding acquisition, S.P. All authors have read and agreed to the published version of the manuscript. 
Funding: This work was supported by Iceland, Liechtenstein and Norway through the EEA Grants and the Technology Agency of the Czech Republic within the framework of the project "inherently flexible aerogels for energy efficient structures (i-FACES)" (Grant number TO01000311, in an amount of $€ 1.04$ Mil.).

Institutional Review Board Statement: Not applicable.

Informed Consent Statement: Not applicable.

Conflicts of Interest: The authors declare no conflict of interest.

\section{References}

1. Kurundawade, S.R.; Malladi, R.S.; Kulkarni, R.M.; Khan, A.A.P. Natural aerogels for pollutant removal. In Advances in Aerogel Composites for Environmental Remediation; Elsevier: Amsterdam, The Netherlands, 2021; pp. 19-32.

2. Liu, H.; Du, H.; Zheng, T.; Xu, T.; Liu, K.; Ji, X.; Zhang, X.; Si, C. Recent progress in cellulose based composite foams and aerogels for advanced energy storage devices. Chem. Eng. J. 2021, 426, 130817. [CrossRef]

3. Amor, N.; Noman, M.T.; Petru, M. Classification of Textile Polymer Composites: Recent Trends and Challenges. Polymers 2021, 13, 2592. [CrossRef]

4. Ashraf, M.A.; Wiener, J.; Farooq, A.; Saskova, J.; Noman, M.T. Development of maghemite glass fibre nanocomposite for adsorptive removal of methylene blue. Fibers Polym. 2018, 19, 1735-1746. [CrossRef]

5. Yang, M.; Choy, K.-l. A nature-derived, flexible and three dimensional (3D) nano-composite for chronic wounds pH monitoring. Mater. Lett. 2021, 288, 129335. [CrossRef]

6. Ahmad, V.; Ahmad, A.; Khan, S.A.; Ahmad, A.; Abuzinadah, M.F.; Karim, S.; Jamal, Q.M.S. Biomedical applications of aerogel. In Advances in Aerogel Composites for Environmental Remediation; Elsevier: Amsterdam, The Netherlands, 2021; pp. 33-48.

7. Siddique, J.A.; Ansari, S.P.; Yadav, M. Carbon aerogel composites for gas sensing. In Advances in Aerogel Composites for Environmental Remediation; Elsevier: Amsterdam, The Netherlands, 2021; pp. 49-73.

8. Qin, L.; Yang, D.; Zhang, M.; Zhao, T.; Luo, Z.; Yu, Z.-Z. Superelastic and ultralight electrospun carbon nanofiber/MXene hybrid aerogels with anisotropic microchannels for pressure sensing and energy storage. J. Colloid Interface Sci. 2021, 589, 264-274. [CrossRef]

9. Wang, Z.; Tammela, P.; Strømme, M.; Nyholm, L. Cellulose-based supercapacitors: Material and performance considerations. Adv. Energy Mater. 2017, 7, 1700130. [CrossRef]

10. Asmussen, R.M.; Matyáš, J.; Qafoku, N.P.; Kruger, A.A. Silver-functionalized silica aerogels and their application in the removal of iodine from aqueous environments. J. Hazard. Mater. 2019, 379, 119364. [CrossRef]

11. Noman, M.T.; Amor, N.; Petru, M.; Mahmood, A.; Kejzlar, P. Photocatalytic Behaviour of Zinc Oxide Nanostructures on Surface Activation of Polymeric Fibres. Polymers 2021, 13, 1227. [CrossRef]

12. Yang, J.; Zhang, E.; Li, X.; Zhang, Y.; Qu, J.; Yu, Z.-Z. Cellulose/graphene aerogel supported phase change composites with high thermal conductivity and good shape stability for thermal energy storage. Carbon 2016, 98, 50-57. [CrossRef]

13. Ansari, S.P.; Husain, A.; Shariq, M.U.; Ansari, M.O. Conducting polymer-based aerogels for energy and environmental remediation. In Advances in Aerogel Composites for Environmental Remediation; Elsevier: Amsterdam, The Netherlands, $2021 ;$ pp. 75-86.

14. Shi, K.; Huang, X.; Sun, B.; Wu, Z.; He, J.; Jiang, P. Cellulose/ $\mathrm{BaTiO}_{3}$ aerogel paper based flexible piezoelectric nanogenerators and the electric coupling with triboelectricity. Nano Energy 2019, 57, 450-458. [CrossRef]

15. Jiang, S.; Zhang, M.; Jiang, W.; Xu, Q.; Yu, J.; Liu, L.; Liu, L. Multiscale nanocelluloses hybrid aerogels for thermal insulation: The study on mechanical and thermal properties. Carbohydr. Polym. 2020, 247, 116701. [CrossRef]

16. Noman, M.T.; Petru, M.; Louda, P.; Kejzlar, P. Woven textiles coated with zinc oxide nanoparticles and their thermophysiological comfort properties. J. Nat. Fibers 2021, 18, 1-14. [CrossRef]

17. Zhang, X.; Zhou, J.; Zheng, Y.; Wei, H.; Su, Z. Graphene-based hybrid aerogels for energy and environmental applications. Chem. Eng. J. 2021, 420, 129700. [CrossRef]

18. Yang, J.; Li, Y.; Zheng, Y.; Xu, Y.; Zheng, Z.; Chen, X.; Liu, W. Versatile aerogels for sensors. Small 2019, 15, 1902826. [CrossRef]

19. Rashidi, S.; Esfahani, J.A.; Rashidi, A. A review on the applications of porous materials in solar energy systems. Renew. Sustain. Energy Rev. 2017, 73, 1198-1210. [CrossRef]

20. Noman, M.T.; Petru, M.; Amor, N.; Louda, P. Thermophysiological comfort of zinc oxide nanoparticles coated woven fabrics. Sci. Rep. 2020, 10, 21080. [CrossRef]

21. Noman, M.T.; Petru, M.; Amor, N.; Yang, T.; Mansoor, T. Thermophysiological comfort of sonochemically synthesized nano TiO 2 coated woven fabrics. Sci. Rep. 2020, 10, 17204. [CrossRef]

22. Rashidi, S.; Esfahani, J.A.; Karimi, N. Porous materials in building energy technologies-A review of the applications, modelling and experiments. Renew. Sustain. Energy Rev. 2018, 91, 229-247. [CrossRef]

23. Jafari, S.; Derakhshankhah, H.; Alaei, L.; Fattahi, A.; Varnamkhasti, B.S.; Saboury, A.A. Mesoporous silica nanoparticles for therapeutic/diagnostic applications. Biomed. Pharmacother. 2019, 109, 1100-1111. [CrossRef]

24. Soorbaghi, F.P.; Isanejad, M.; Salatin, S.; Ghorbani, M.; Jafari, S.; Derakhshankhah, H. Bioaerogels: Synthesis approaches, cellular uptake, and the biomedical applications. Biomed. Pharmacother. 2019, 111, 964-975. [CrossRef] 
25. Javadi, A.; Zheng, Q.; Payen, F.; Javadi, A.; Altin, Y.; Cai, Z.; Sabo, R.; Gong, S. Polyvinyl alcohol-cellulose nanofibrils-graphene oxide hybrid organic aerogels. ACS Appl. Mater. Interfaces 2013, 5, 5969-5975. [CrossRef] [PubMed]

26. Zhao, S.; Siqueira, G.; Drdova, S.; Norris, D.; Ubert, C.; Bonnin, A.; Galmarini, S.; Ganobjak, M.; Pan, Z.; Brunner, S. Additive manufacturing of silica aerogels. Nature 2020, 584, 387-392. [CrossRef] [PubMed]

27. Cai, B.; Hübner, R.; Sasaki, K.; Zhang, Y.; Su, D.; Ziegler, C.; Vukmirovic, M.B.; Rellinghaus, B.; Adzic, R.R.; Eychmüller, A. Core-shell structuring of pure metallic aerogels towards highly efficient platinum utilization for the oxygen reduction reaction. Angew. Chem. Int. Ed. 2018, 57, 2963-2966. [CrossRef]

28. Biener, J.; Stadermann, M.; Suss, M.; Worsley, M.A.; Biener, M.M.; Rose, K.A.; Baumann, T.F. Advanced carbon aerogels for energy applications. Energy Environ. Sci. 2011, 4, 656-667. [CrossRef]

29. Subrahmanyam, K.S.; Sarma, D.; Malliakas, C.D.; Polychronopoulou, K.; Riley, B.J.; Pierce, D.A.; Chun, J.; Kanatzidis, M.G. Chalcogenide aerogels as sorbents for radioactive iodine. Chem. Mater. 2015, 27, 2619-2626. [CrossRef]

30. Wang, X.; Jana, S.C. Synergistic hybrid organic-inorganic aerogels. ACS Appl. Mater. Interfaces 2013, 5, 6423-6429. [CrossRef]

31. Ansari, M.O.; Khan, A.A.P.; Ansari, M.S.; Khan, A.; Kulkarni, R.M.; Bhamare, V.S. Aerogel and its composites: Fabrication and properties. In Advances in Aerogel Composites for Environmental Remediation; Elsevier: Amsterdam, The Netherlands, $2021 ;$ pp. 1-17.

32. Noman, M.T.; Militky, J.; Wiener, J.; Saskova, J.; Ashraf, M.A.; Jamshaid, H.; Azeem, M. Sonochemical synthesis of highly crystalline photocatalyst for industrial applications. Ultrasonics 2018, 83, 203-213. [CrossRef] [PubMed]

33. Berardi, U. The benefits of using aerogel-enhanced systems in building retrofits. Energy Procedia 2017, 134, 626-635. [CrossRef]

34. Gurav, J.L.; Jung, I.-K.; Park, H.-H.; Kang, E.S.; Nadargi, D.Y. Silica aerogel: Synthesis and applications. J. Nanomater. 2010, 2010, 409310. [CrossRef]

35. Liu, Z.-H.; Ding, Y.-D.; Wang, F.; Deng, Z.-P. Thermal insulation material based on $\mathrm{SiO}_{2}$ aerogel. Constr. Build. Mater. 2016, 122, 548-555. [CrossRef]

36. Hanif, A.; Diao, S.; Lu, Z.; Fan, T.; Li, Z. Green lightweight cementitious composite incorporating aerogels and fly ash cenospheresMechanical and thermal insulating properties. Constr. Build. Mater. 2016, 116, 422-430. [CrossRef]

37. Al Zaidi, I.K.; Demirel, B.; Atis, C.D.; Akkurt, F. Investigation of mechanical and thermal properties of nano $\mathrm{SiO}_{2} / \mathrm{hydrophobic}$ silica aerogel co-doped concrete with thermal insulation properties. Struct. Concr. 2020, 21, 1123-1133. [CrossRef]

38. Biesmans, G.; Mertens, A.; Duffours, L.; Woignier, T.; Phalippou, J. Polyurethane based organic aerogels and their transformation into carbon aerogels. J. Non-Cryst. Solids 1998, 225, 64-68. [CrossRef]

39. Lee, J.-H.; Park, S.-J. Recent advances in preparations and applications of carbon aerogels: A review. Carbon 2020, 163, 1-18. [CrossRef]

40. Zhang, S.; Fu, R.; Wu, D.; Xu, W.; Ye, Q.; Chen, Z. Preparation and characterization of antibacterial silver-dispersed activated carbon aerogels. Carbon 2004, 42, 3209-3216. [CrossRef]

41. Krumm, M.; Pueyo, C.L.; Polarz, S. Monolithic zinc oxide aerogels from organometallic sol-gel precursors. Chem. Mater. 2010, 22, 5129-5136. [CrossRef]

42. Yue, X.; Xiang, J.; Chen, J.; Li, H.; Qiu, Y.; Yu, X. High surface area, high catalytic activity titanium dioxide aerogels prepared by solvothermal crystallization. J. Mater. Sci. Technol. 2020, 47, 223-230. [CrossRef]

43. Mirtaghavi, A.; Luo, J.; Muthuraj, R. Recent Advances in Porous 3D Cellulose Aerogels for Tissue Engineering Applications: A Review. J. Compos. Sci. 2020, 4, 152. [CrossRef]

44. Ko, E.; Kim, H. Preparation of chitosan aerogel crosslinked in chemical and ionical ways by non-acid condition for wound dressing. Int. J. Biol. Macromol. 2020, 164, 2177-2185. [CrossRef] [PubMed]

45. Wang, Y.; Xiang, F.; Wang, W.; Wang, W.; Su, Y.; Jiang, F.; Chen, S.; Riffat, S. Sound absorption characteristics of KGM-based aerogel. Int. J. Low-Carbon Technol. 2020, 15, 450-457. [CrossRef]

46. Maleki, H.; Durães, L.; Portugal, A. An overview on silica aerogels synthesis and different mechanical reinforcing strategies. J. Non-Cryst. Solids 2014, 385, 55-74. [CrossRef]

47. Noman, M.T.; Amor, N.; Petru, M. Synthesis and applications of ZnO nanostructures (ZONSs): A review. Crit. Rev. Solid State Mater. Sci. 2021, 1-43. [CrossRef]

48. Noman, M.T.; Ashraf, M.A.; Ali, A. Synthesis and applications of nano- $\mathrm{TiO}_{2}$ : A review. Environ. Sci. Pollut. Res. 2019, 26, 3262-3291. [CrossRef]

49. Amor, N.; Noman, M.T.; Petru, M. Prediction of functional properties of nano $\mathrm{TiO}_{2}$ coated cotton composites by artificial neural network. Sci. Rep. 2021, 11, 12235. [CrossRef]

50. Noman, M.T.; Ashraf, M.A.; Jamshaid, H.; Ali, A. A novel green stabilization of $\mathrm{TiO}_{2}$ nanoparticles onto cotton. Fibers Polym. 2018, 19, 2268-2277. [CrossRef]

51. Qian, F.; Troksa, A.; Fears, T.M.; Nielsen, M.H.; Nelson, A.J.; Baumann, T.F.; Kucheyev, S.O.; Han, T.Y.-J.; Bagge-Hansen, M. Gold aerogel monoliths with tunable ultralow densities. Nano Lett. 2019, 20, 131-135. [CrossRef] [PubMed]

52. Qian, F.; Lan, P.C.; Freyman, M.C.; Chen, W.; Kou, T.; Olson, T.Y.; Zhu, C.; Worsley, M.A.; Duoss, E.B.; Spadaccini, C.M. Ultralight conductive silver nanowire aerogels. Nano Lett. 2017, 17, 7171-7176. [CrossRef] [PubMed]

53. Yan, P.; Brown, E.; Su, Q.; Li, J.; Wang, J.; Xu, C.; Zhou, C.; Lin, D. 3D printing hierarchical silver nanowire aerogel with highly compressive resilience and tensile elongation through tunable poisson's ratio. Small 2017, 13, 1701756. [CrossRef]

54. Xu, X.; Wang, R.; Nie, P.; Cheng, Y.; Lu, X.; Shi, L.; Sun, J. Copper nanowire-based aerogel with tunable pore structure and its application as flexible pressure sensor. ACS Appl. Mater. Interfaces 2017, 9, 14273-14280. [CrossRef] 
55. Schwertfeger, F.; Frank, D.; Schmidt, M. Hydrophobic waterglass based aerogels without solvent exchange or supercritical drying. J. Non-Cryst. Solids 1998, 225, 24-29. [CrossRef]

56. Carlson, G.; Lewis, D.; McKinley, K.; Richardson, J.; Tillotson, T. Aerogel commercialization: Technology, markets and costs. J. Non-Cryst. Solids 1995, 186, 372-379. [CrossRef]

57. Adhikary, S.K.; Ashish, D.K.; Rudžionis, Ž. Aerogel based thermal insulating cementitious composites: A review. Energy Build. 2021, 245, 111058. [CrossRef]

58. Lei, Y.; Hu, Z.; Cao, B.; Chen, X.; Song, H. Enhancements of thermal insulation and mechanical property of silica aerogel monoliths by mixing graphene oxide. Mater. Chem. Phys. 2017, 187, 183-190. [CrossRef]

59. Patil, S.P.; Shendye, P.; Markert, B. Molecular dynamics simulations of silica aerogel nanocomposites reinforced by glass fibers, graphene sheets and carbon nanotubes: A comparison study on mechanical properties. Compos. Part B Eng. 2020, 190, 107884. [CrossRef]

60. Li, Z.; Gong, L.; Cheng, X.; He, S.; Li, C.; Zhang, H. Flexible silica aerogel composites strengthened with aramid fibers and their thermal behavior. Mater. Des. 2016, 99, 349-355. [CrossRef]

61. Li, Z.; Cheng, X.; He, S.; Shi, X.; Gong, L.; Zhang, H. Aramid fibers reinforced silica aerogel composites with low thermal conductivity and improved mechanical performance. Compos. Part A Appl. Sci. Manuf. 2016, 84, 316-325. [CrossRef]

62. Maleki, H.; Durães, L.; García-González, C.A.; Del Gaudio, P.; Portugal, A.; Mahmoudi, M. Synthesis and biomedical applications of aerogels: Possibilities and challenges. Adv. Colloid Interface Sci. 2016, 236, 1-27. [CrossRef]

63. Noman, M.T.; Wiener, J.; Saskova, J.; Ashraf, M.A.; Vikova, M.; Jamshaid, H.; Kejzlar, P. In-situ development of highly photocatalytic multifunctional nanocomposites by ultrasonic acoustic method. Ultrason. Sonochem. 2018, 40, 41-56. [CrossRef] [PubMed]

64. Balram, D.; Lian, K.-Y.; Sebastian, N.; Al-Mubaddel, F.S.; Noman, M.T. Bi-functional renewable biopolymer wrapped CNFs/Ag doped spinel cobalt oxide as a sensitive platform for highly toxic nitroaromatic compound detection and degradation. Chemosphere 2021, 132998. [CrossRef]

65. Muñoz-Ruíz, A.; Escobar-García, D.M.; Quintana, M.; Pozos-Guillén, A.; Flores, H. Synthesis and characterization of a new collagen-alginate aerogel for tissue engineering. J. Nanomater. 2019, 2019, 2875375. [CrossRef]

66. Osorio, D.A.; Lee, B.E.; Kwiecien, J.M.; Wang, X.; Shahid, I.; Hurley, A.L.; Cranston, E.D.; Grandfield, K. Cross-linked cellulose nanocrystal aerogels as viable bone tissue scaffolds. Acta Biomater. 2019, 87, 152-165. [CrossRef] [PubMed]

67. Reyes-Peces, M.V.; Pérez-Moreno, A.; de-Los-Santos, D.M.; Mesa-Díaz, M.d.M.; Pinaglia-Tobaruela, G.; Vilches-Pérez, J.I.; Fernández-Montesinos, R.; Salido, M.; de la Rosa-Fox, N.; Piñero, M. Chitosan-GPTMS-Silica Hybrid Mesoporous Aerogels for Bone Tissue Engineering. Polymers 2020, 12, 2723. [CrossRef]

68. Groult, S.; Buwalda, S.; Budtova, T. Pectin hydrogels, aerogels, cryogels and xerogels: Influence of drying on structural and release properties. Eur. Polym. J. 2021, 149, 110386. [CrossRef]

69. Rostamitabar, M.; Subrahmanyam, R.; Gurikov, P.; Seide, G.; Jockenhoevel, S.; Ghazanfari, S. Cellulose aerogel micro fibers for drug delivery applications. Mater. Sci. Eng. C 2021, 127, 112196. [CrossRef] [PubMed]

70. De Marco, I.; Miranda, S.; Riemma, S.; Iannone, R. LCA of starch aerogels for biomedical applications. Chem. Eng. Trans. 2016, $49,319-324$.

71. Saadatnia, Z.; Mosanenzadeh, S.G.; Chin, M.M.; Naguib, H.E.; Popovic, M.R. Flexible, Air Dryable, and Fiber Modified AerogelBased Wet Electrode for Electrophysiological Monitoring. IEEE Trans. Biomed. Eng. 2020, 68, 1820-1827. [CrossRef]

72. Tetik, H.; Zhao, K.; Shah, N.; Lin, D. 3D freeze-printed cellulose-based aerogels: Obtaining truly 3D shapes, and functionalization with cross-linking and conductive additives. J. Manuf. Process. 2021, 68, 445-453. [CrossRef]

73. Amor, N.; Noman, M.T.; Petru, M. Prediction of Methylene Blue Removal by Nano $\mathrm{TiO}_{2}$ Using Deep Neural Network. Polymers 2021, 13, 3104. [CrossRef]

74. Noman, M.T.; Petrů, M. Functional properties of sonochemically synthesized zinc oxide nanoparticles and cotton composites. Nanomaterials 2020, 10, 1661. [CrossRef]

75. Balram, D.; Lian, K.-Y.; Sebastian, N.; Al-Mubaddel, F.S.; Noman, M.T. Ultrasensitive detection of food colorant sunset yellow using nickel nanoparticles promoted lettuce-like spinel $\mathrm{Co}_{3} \mathrm{O}_{4}$ anchored GO nanosheets. Food Chem. Toxicol. 2021, 159, 112725. [CrossRef]

76. Strobach, E.; Bhatia, B.; Yang, S.; Zhao, L.; Wang, E.N. High temperature annealing for structural optimization of silica aerogels in solar thermal applications. J. Non-Cryst. Solids 2017, 462, 72-77. [CrossRef]

77. Li, Q.; Zhang, Y.; Wen, Z.-X.; Qiu, Y. An evacuated receiver partially insulated by a solar transparent aerogel for parabolic trough collector. Energy Convers. Manag. 2020, 214, 112911. [CrossRef]

78. Han, L.; Dong, L.; Zhang, H.; Li, F.; Tian, L.; Li, G.; Jia, Q.; Zhang, S. Thermal insulation TiN aerogels prepared by a combined freeze-casting and carbothermal reduction-nitridation technique. J. Eur. Ceram. Soc. 2021, 41, 5127-5137. [CrossRef]

79. Liu, S.; Wu, X.; Li, Y.; Cui, S.; Shen, X.; Tan, G. Hydrophobic in-situ $\mathrm{SiO}_{2}-\mathrm{TiO}_{2}$ composite aerogel for heavy oil thermal recovery: Synthesis and high temperature performance. Appl. Therm. Eng. 2021, 190, 116745. [CrossRef]

80. Long, S.; Feng, Y.; He, F.; Zhao, J.; Bai, T.; Lin, H.; Cai, W.; Mao, C.; Chen, Y.; Gan, L. Biomass-derived, multifunctional and wave-layered carbon aerogels toward wearable pressure sensors, supercapacitors and triboelectric nanogenerators. Nano Energy 2021, 85, 105973. [CrossRef]

81. Liu, X.; Sheng, G.; Zhong, M.; Zhou, X. Dispersed and size-selected $\mathrm{WO}_{3}$ nanoparticles in carbon aerogel for supercapacitor applications. Mater. Des. 2018, 141, 220-229. [CrossRef] 
82. Muniyandi, T.M.; Balamurugan, S.; Naresh, N.; Prakash, I.; Venkatesh, R.; Deshpande, U.; Satyanarayana, N. $\mathrm{Li}_{2} \mathrm{FeSiO}_{4} / \mathrm{C}$ aerogel: A promising nanostructured cathode material for lithium-ion battery applications. J. Alloys Compd. 2021, 887, 161341. [CrossRef]

83. Chen, J.; Chen, Y.; Li, C.; Hu, Y.; Fang, L.; Yang, Q.; Shi, Z.; Xiong, C. Incorporation of $\mathrm{Fe}_{3} \mathrm{O}_{4}$ nanoparticles in three-dimensional carbon nanofiber/carbon nanotube aerogels for high-performance anodes of lithium-ion batteries. Colloids Surf. A Physicochem. Eng. Asp. 2021, 631, 127716. [CrossRef]

84. Jiang, X.; Ban, C.; Li, L.; Li, H.; Hao, J.; Chen, W.; Liu, X. Design of thermoelectric battery based on $\mathrm{BN}^{2}$ aerogels and $\mathrm{Bi}_{2} \mathrm{Te}_{3}$ composites. J. Alloys Compd. 2021, 887, 161280. [CrossRef]

85. Bhamare, V.S.; Kulkarni, R.M.; Khan, A.A.P. Adsorptive removals of pollutants using aerogels and its composites. In Advances in Aerogel Composites for Environmental Remediation; Elsevier: Amsterdam, The Netherlands, 2021; pp. 171-199.

86. Eniola, J.O.; Ansari, M.O.; Barakat, M.; Kumar, R. Aerogels in photocatalysis. In Advances in Aerogel Composites for Environmental Remediation; Elsevier: Amsterdam, The Netherlands, 2021; pp. 87-108.

87. Moheman, A.; Bhawani, S.A.; Tariq, A. Aerogels for waterborne pollutants purification. In Advances in Aerogel Composites for Environmental Remediation; Elsevier: Amsterdam, The Netherlands, 2021; pp. 109-124.

88. Noman, M.T.; Petru, M.; Militký, J.; Azeem, M.; Ashraf, M.A. One-Pot Sonochemical Synthesis of ZnO Nanoparticles for Photocatalytic Applications, Modelling and Optimization. Materials 2020, 13, 14. [CrossRef] [PubMed]

89. Rohilla, S.; Gupta, A.; Kumar, V.; Kumari, S.; Petru, M.; Amor, N.; Noman, M.T.; Dalal, J. Excellent UV-Light Triggered

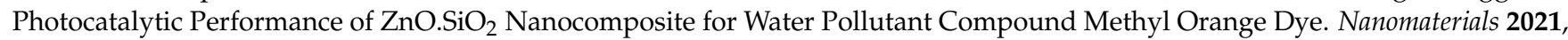
11, 2548. [CrossRef] [PubMed]

90. Golder, S.; Narayanan, R.; Hossain, M.; Islam, M.R. Experimental and CFD Investigation on the Application for Aerogel Insulation in Buildings. Energies 2021, 14, 3310. [CrossRef]

91. Qi, Z.; Liu, H.; Wang, J.; Yan, F. The enhanced transfer behavior and tribological properties in deep sea environment of poly (butylene terephthalate) composites reinforced by silica nanoaerogels. Tribol. Int. 2021, 160, 107051. [CrossRef]

92. Amor, N.; Noman, M.T.; Petru, M.; Mahmood, A.; Ismail, A. Neural network-crow search model for the prediction of functional properties of nano $\mathrm{TiO}_{2}$ coated cotton composites. Sci. Rep. 2021, 11, 13649.

93. Noman, M.T.; Petru, M. Effect of Sonication and $\mathrm{Nano} \mathrm{TiO}_{2}$ on Thermophysiological Comfort Properties of Woven Fabrics. ACS Omega 2020, 5, 11481-11490. [CrossRef]

94. Alizadeh, T.; Hamedsoltani, L. Managing of gas sensing characteristic of a reduced graphene oxide based gas sensor by the change in synthesis condition: A new approach for electronic nose design. Mater. Chem. Phys. 2016, 183, 181-190. [CrossRef]

95. Thubsuang, U.; Sukanan, D.; Sahasithiwat, S.; Wongkasemjit, S.; Chaisuwan, T. Highly sensitive room temperature organic vapor sensor based on polybenzoxazine-derived carbon aerogel thin film composite. Mater. Sci. Eng. B 2015, 200, 67-77. [CrossRef]

96. Wu, J.; Li, Z.; Xie, X.; Tao, K.; Liu, C.; Khor, K.A.; Miao, J.; Norford, L.K. 3D superhydrophobic reduced graphene oxide for activated $\mathrm{NO}_{2}$ sensing with enhanced immunity to humidity. J. Mater. Chem. A 2018, 6, 478-488. [CrossRef]

97. Yang, F.; Zhu, J.; Zou, X.; Pang, X.; Yang, R.; Chen, S.; Fang, Y.; Shao, T.; Luo, X.; Zhang, L. Three-dimensional TiO $2 / \mathrm{SiO}_{2}$ composite aerogel films via atomic layer deposition with enhanced $\mathrm{H}_{2} \mathrm{~S}$ gas sensing performance. Ceram. Int. 2018, 44, 1078-1085. [CrossRef]

98. Liu, X.; Sun, J.; Zhang, X. Novel 3D graphene aerogel-ZnO composites as efficient detection for $\mathrm{NO}_{2}$ at room temperature. Sens. Actuators B Chem. 2015, 211, 220-226. [CrossRef]

99. Wang, R.; Li, G.; Dong, Y.; Chi, Y.; Chen, G. Carbon quantum dot-functionalized aerogels for $\mathrm{NO}_{2}$ gas sensing. Anal. Chem. 2013, 85, 8065-8069. [CrossRef]

100. Wang, C.-T.; Wu, C.-L. Electrical sensing properties of silica aerogel thin films to humidity. Thin Solid Films 2006, 496, 658-664. [CrossRef]

101. Alizadeh, T.; Ahmadian, F. Thiourea-treated graphene aerogel as a highly selective gas sensor for sensing of trace level of ammonia. Anal. Chim. Acta 2015, 897, 87-95. [CrossRef] [PubMed]

102. Gao, H.; Ma, Y.; Song, P.; Leng, J.; Wang, Q. Gas sensor based on $\mathrm{rGO} / \mathrm{ZnO}$ aerogel for efficient detection of $\mathrm{NO}_{2}$ at room temperature. J. Mater. Sci. Mater. Electron. 2021, 32, 10058-10069. [CrossRef]

103. Bibi, A.; Rubio, Y.R.M.; Santiago, K.S.; Jia, H.-W.; Ahmed, M.M.; Lin, Y.-F.; Yeh, J.-M. $\mathrm{H}_{2} \mathrm{~S}-$ Sensing Studies Using Interdigitated Electrode with Spin-Coated Carbon Aerogel-Polyaniline Composites. Polymers 2021, 13, 1457. [CrossRef] [PubMed]

104. Zhu, H.; Dai, S.; Zhou, X.; Dong, X.; Jiang, Y.; Chen, Y.; Yuan, N.; Ding, J. A highly sensitive piezoresistive sensor based on CNT-rGO aerogel for human motion detection. J. Compos. Mater. 2021, 55, 00219983211020110. [CrossRef]

105. Cao, X.; Zhang, J.; Chen, S.; Varley, R.J.; Pan, K. 1D/2D nanomaterials synergistic, compressible, and response rapidly 3D graphene aerogel for piezoresistive sensor. Adv. Funct. Mater. 2020, 30, 2003618. [CrossRef]

106. Wei, S.; Qiu, X.; An, J.; Chen, Z.; Zhang, X. Highly sensitive, flexible, green synthesized graphene/biomass aerogels for pressure sensing application. Compos. Sci. Technol. 2021, 207, 108730. [CrossRef]

107. Bi, Y.; Hei, Y.; Wang, N.; Liu, J.; Ma, C.-B. Synthesis of a clustered carbon aerogel interconnected by carbon balls from the biomass of taros for construction of a multi-functional electrochemical sensor. Anal. Chim. Acta 2021, 1164, 338514. [CrossRef] [PubMed]

108. Yang, Z.; Li, H.; Zhang, S.; Lai, X.; Zeng, X. Superhydrophobic MXene@ carboxylated carbon nanotubes/carboxymethyl chitosan aerogel for piezoresistive pressure sensor. Chem. Eng. J. 2021, 425, 130462. [CrossRef] 